Este periódico científico, que agora chega às mãos do leitor, tem como finalidade analisar questões relevantes nos campos da Educação e da Saúde, relacionando essas práticas sociais com o mundo do trabalho, sobretudo em suas formas contemporâneas.

Trata-se da revista Trabalho, Educação e Saúde, que se institui como um projeto, ao mesmo tempo técnico e político, de divulgação de conhecimento e pensamento crítico, a ser construído ao longo do tempo e dos números que forem publicados. É um projeto que faz parte da consolidação da Escola Politécnica de Saúde Joaquim Venâncio, da Fundação Oswaldo Cruz, como instituição pública e estratégica que apóia, nacionalmente, o campo da Educação Profissional em Saúde.

Trabalho, portanto, que segue e fortalece a tradição da Fundação Oswaldo Cruz em seu constante compromisso com as políticas de Saúde Pública no Brasil. Tendo esse horizonte como meta, pretende-se publicar, na revista, trabalhos avaliados, de reconhecido valor teórico, fundamentando o projeto com o necessário rigor, dando assim espaço para a articulação das abordagens e dos diálogos críticos, sempre necessários para fortalecer e consolidar uma esfera pública de fato democrática.

\title{
André Malhão
}

Diretor da Escola Politécnica

de Saúde Joaquim Venâncio, Fiocruz 